\title{
The influence of job crafting on the quality of care provided by nursing home employees: The moderating effect of organizational identification
}

\author{
Marina Romeo ${ }^{1} \cdot$ Montserrat Yepes-Baldó $^{1}$ (D) Maria Nordin ${ }^{2} \cdot$ Kristina Westerberg $^{2} \cdot$ Robert Lundmark $^{2}$. \\ Pamela Morales ${ }^{3}$
}

Accepted: 14 September 2021

(C) The Author(s) 2021

\begin{abstract}
Our goal was to analyze the positive effect of job crafting activities involving nursing home employees on their perceived quality of care, and the moderating effect of organizational identification. A two-wave non-experimental design (with an interval of 12 months) was used. The Job Crafting Questionnaire, the Identification-Commitment Inventory, and the Quality of Care Questionnaire (QoC) were administered to 226 nursing home employees in two waves. The results of the hierarchical regression analyses found significant association between job crafting subdimensions and quality of care twelve months later. Organizational identification was shown to play a moderating role in these relationships when analyzing the effect of cognitive crafting. In this sense, the effect of cognitive crafting on quality of care is only found with high levels of identification. The findings highlight the importance of the job crafting dimensions (task, relational and cognitive) when it comes to enhancing quality of care in residential homes for the elderly. This is especially relevant for cognitive crafting among employees with high levels of organizational identification. This research provides managers with guidance when allocating job crafting opportunities aimed at making improvements in quality of care. In this respect, organizations must offer job crafting training to stimulate and support their employees and, on the other hand, managers should encourage employees to craft their jobs, gearing their needs, abilities, and goals to corporate values and competencies.
\end{abstract}

Keywords Job crafting · Perceived quality of care · Organizational identification · Elderly care $\cdot$ Nursing home employees

\section{Introduction}

Marina Romeo

mromeo@ub.edu

Montserrat Yepes-Baldó

myepes@ub.edu

Maria Nordin

maria.nordin@umu.se

Kristina Westerberg

kristina.westerberg@umu.se

Robert Lundmark

robert.lundmark@umu.se

1 Universitat de Barcelona, Barcelona, Spain

2 Umeå Universitet, Umeå, Sweden

3 Barcelona, Spain
In Europe, the impact of current demographic change has resulted in an increased demand for nursing home and expanded formal care services (Genet et al., 2012). This job sector presents physically and psychosocially demanding work conditions (Brulin et al., 2000), which include high workloads (Bakker et al., 2005), time pressure (Tadić, 2019), an isolated work environment, and a lack of peer and leader support (Westerberg \& Tafvelin, 2014).

Brulin et al. (2000) have empirically confirmed that perceived poor working conditions and high job demands often lead to stress in the nursing profession, putting the safekeeping and quality of care standards at risk. Several authors, such as Neves et al. (2020), have pointed out that quality of care "is a global health priority for health organizations" (Neves et al., 2020, p. 4) and it is considered an important indicator of job performance in the nursing home context (Wagner et al., 2001). 
A review of the literature reveals that one way of positively affecting perceived quality of care is through job crafting (Yepes-Baldó et al., 2018). Job crafting is a proactive behavior that allows employees to redesign the job by "initiating changes in tasks and interactions or even altering thoughts about the work" (Romeo et al., 2018, p. 415). It has three facets: task, relational and cognitive crafting (Wrzeniewski \& Dutton, 2001; Zhang \& Parker, 2019). In other words, job crafting can better align the job characteristics linked to cognitive, relational, and task boundaries and thus enhance quality of care.

Furthermore, several studies indicate that employees' perception of organizational identification, defined as an active process by which individuals link themselves to the organization, is associated with positive organizational attitudes (van Knippenberg \& van Schie, 2000) and behaviors, such as performance (Ang et al., 2013; Bobbio \& Manganelli, 2015; Tummers et al., 2013; Yaghoubi et al., 2013) and proactive behaviors (Tyler \& Blader, 2003). According to the proactive behavior perspective, it can be predicted that "job crafting is likely to have a positive relationship with organizational identification" (Kilic et al., 2020, p. 204). For this reason, those employees highly identified with their organizations will be more proactive when looking for the quality of the service they perform. The research conducted by Bacaksiz et al. (2017) indicated that job crafting, organizational identification and nurses' performance had significant correlations, being the strongest correlation observed between organizational identification and employee performance. As pointed out by Niessen et al. (2016) and Hur et al. (2017), only a limited number of studies have investigated the relationship between job crafting and organizational identification and more research is needed "for revealing the correlation between the concepts of organizational identification and job crafting, which would increase the employee performance" (Bacaksiz et al., 2017, p. 257).

In this sense, the goal of this research was to analyze the positive effect of job crafting activities involving nursing home employees on their perceived quality of care and explore the moderating effect of organizational identification. This research examined the dynamic nature of these processes, using a two-wave design to clearly confirm the relations between job crafting, identification, and perceived quality of care over a period of time.

\section{Literature review and hypotheses development}

\section{Quality of care and job crafting}

As pointed out above, quality of care is a priority for health organizations and is defined as "the extent to which health care services provided to individuals and patient populations improve desired health outcomes" (World Health Organization [WHO], 2016, p. 14).

Quality of care is the result of cooperation between patients, clients, and staff (Roberts, 1987). However, the scientific literature shows that it is usually assessed only by care recipients and family members (Lood et al., 2019; Scheepers et al., 2014; Verho \& Arnetz, 2003), with Boumans et al. (2005) and Hasson and Arnetz (2009) suggesting that their perceptions of quality of care might not be sensitive to actual changes in quality of care. Each stakeholder's perceptions complement the others, although not all are reliable when it comes to enhancing the quality of care. Several studies have demonstrated that quality of care as assessed by hospital care staff can be useful (Aiken et al., 2002; Hasson \& Arnetz, 2009; Mckenzie et al., 2011; Romeo et al., 2018; Stimpfel et al., 2019; Westerberg \& Tafvelin, 2014; Yepes-Baldó et al., 2018). Specifically, Westerberg and Tafvelin (2014) showed that the perceptions of staff provide a more reliable measure of this variable than the clients' point of view. Hasson and Arnetz (2009) highlight that "nurses, as they are proximity close to patients, are able to reliably compare the actual quality of care to recommended standards" (p. 471). Furthermore, Lundgren et al. (2020) point out that clients' perceptions of care may be affected by their interactions with employees. Given these contentions, in this research we decided to assess the quality of care as perceived by nursing staff, because employees know their real working conditions and challenges and the limitations that impact the perceived quality of care they can offer (Mckenzie et al., 2011).

Moore (2018), Dennerstein et al., (2018), Røen et al. (2017), Vernooij-Dassen and Moniz-Cook (2016), and Scheepers et al. (2014) have studied quality of care as an aspect of performance and as an indicator of patient outcome (Purdy et al., 2010). One critical aspect that facilitates quality of care, as stated by Slemp \& Vella-Brodrick (2013), is how employees can be proactive and take the initiative to redesign their work (Slemp \& Vella-Brodrick, 2013), i.e., how employees craft their jobs.

Lichtenthaler and Fischbach (2019) define job crafting as "employee-driven changes in tangible work role boundaries and intangible work role perceptions" (p. 2). In other words, employees can enhance their work identities by internalizing how much their work means to them, expanding or contracting the relational aspects of the job, and the number (more or fewer), scope, or nature of their job tasks (Wrzesniewski et al., 2003, 2010, 2013). In this context job crafting makes "feel employees as 'the architect of their jobs' due to be active participants in the construction of their work" (Berg et al., 2013, p. 96).

Job crafting, as a bottom-up design, modifies tasks that have a direct impact on the meaning of work and alters aspects of the work environment by means of new 
interactions that facilitate positive meanings and provide greater meaningfulness at work. Wrzesniewski et al. (2010) specify three types of job crafting: task, relational, and cognitive. Task crafting involves altering the responsibilities detailed in the formal job description by adding or avoiding new tasks or projects, or allocating more or less time, energy and attention, or redesigning tasks, i.e. "changing certain work procedures that are faulty or proposing innovative solutions to problems at work" (Tims \& Bakker, 2010, p. 1).

Relational crafting is concerned with improving relationships by modifying them to enrich the quality of connections between people. According to Wrzeniewski and Dutton (2001), there are three ways in which employees can craft their interactions with others at work: by building relationships, for instance, by "performing their work with people who make them feel inspired, prided, dignified, and worth" (Berg et al., 2013, p. 10); by reframing relationships, whereby employees craft their work by changing the basics of the relationship to foster more meaningful purpose (Berg et al., 2013); and by adapting relationships, thus changing the purpose of relationships or adding new ones that can unlock meaningfulness through the sharing of valuable help and support among employees (Wrzesniewski et al., 2003).

Finally, cognitive crafting describes the way in which employees can view their work more positively. Berg et al. (2013) mention three ways of experiencing more meaningfulness at work: expanding perceptions, whereby employees keep the holistic purpose of their jobs in mind; focusing perceptions, whereby employees try to "reduce mental scope of the purpose of job on specific tasks and relationships that are significant or valuable" (Berg et al., 2013, p. 12); and linking perceptions, whereby "employees can take advantage their jobs by drawing mental connections between tasks or relationships and interests or aspects of their identities that are meaningful to them" (Berg et al., 2013, p. 95).

From the perspective of the Job Demands and Resources theory (JD-R), it is considered that cognitive crafting is a mere passive adaptation to work, so it cannot be conceived as crafting since it is not a proactive behavior of change (Tims \& Bakker, 2010; Tims et al., 2013). Nevertheless, following the proposal of Zhang and Parker (2019), based on Wrzesniewski et al. (2010), cognitive crafting should be included as part of the construct as "it involves altering how one frames or views their tasks or job, which is self-initiated, self-targeted, intentional, and represents meaningful changes to the job aspects" (Zhang \& Parker, 2019, p. 5).

A recent literature review (Lee \& Lee, 2018) on job crafting and performance found that only two studies had analyzed the relationship between job crafting and quality of care as in-role performance indicators (Leana et al., 2009; Yepes-Baldó et al., 2018). Both studies were based on the perspective of Wrzeniewski and Dutton (2001). Nevertheless, results were not consistent. Yepes-Baldó et al. (2018) and Romeo et al. (2018) have demonstrated positive associations between employees' job crafting and perceived quality of care in the elderly care sector. Contrarily, Leana et al. (2009) found non-significant results when analyzing job crafting from an individual perspective while collaborative crafting was related with quality of care in an early childhood education context. Other studies have shown consistent correlations between job crafting subdimensions (task, relational and cognitive) and in-role performance in different context (Lee \& Lee, 2018), but the definition of in-role performance varies between studies.

These contradictory results suggested the need to further analyze whether job crafting provides higher perceived quality of care and to more clearly evidence the relations established over time in larger samples. In this sense, it is important to take into account that job crafting is also a dynamic process, since it can fluctuate quickly within shorter periods of time, i.e. days or weeks, or unfold gradually over longer periods of time, i.e. months or years (Petrou et al., 2012).

For these reasons, with the aim of overcoming the limitations identified in the abovementioned previous studies (Leana et al., 2009; Romeo et al., 2018; Yepes-Baldó et al., 2018) and to gain a deeper insight into the relationship between job crafting carried out by care staff and quality of care at nursing homes, from the perspective of Wrezniewski and Dutton (2001), this study incorporates the analysis of the relationship between job crafting subdimensions in a first measurement (T1) and perceived quality of care measured twelve months later (T2). Therefore, Hypothesis 1 is posited as follows:

Hypothesis 1: Job crafting (T1) is positively associated with perceived quality of care (T2).

H1.a: Task crafting (T1) is positively associated with perceived quality of care (T2).

H1.b: Relational crafting (T1) is positively associated with perceived quality of care (T2).

H1.c: Cognitive crafting (T1) is positively associated with perceived quality of care (T2).

\section{The moderating role of organizational identification}

Organizational identification is an "ongoing process, where individuals tend to link themselves to a certain social element" (Hamzagić, 2018, p. 31). Organizational identification and organizational commitment attempt to clarify the link between employees and their organization. Nevertheless, as pointed out by Van Knippenberg and Sleebos (2006), they are different concepts. In this sense, "commitment is more exchange-based than identification, because identification is self-referential whereas commitment is not" (Van Knippenberg \& Sleebos, 2006, p. 579). 
Romeo et al. (2011) confirmed this relationship although the authors stated that both constructs were operatively different.

According to Quijano et al. (2000), organizational identification is a type of link between employees and the organization that implies cognition, affection and desire, and it comprises three dimensions: Pride, which "implies selfesteem for being part of the group" (Romeo et al., 2011, p. 904); categorization, which "means being aware of belonging" (Romeo et al., 2011, p. 904); and cohesion, which "implies desire of continuous belonging to the organization" (Romeo et al., 2011, p. 904).

Several authors have pointed out the importance of this variable (Ang et al., 2013; Bobbio \& Manganelli, 2015; Tummers et al., 2013; Yaghoubi et al., 2013) and shown that employees with an increased perception of organizational identification establish positive attitudes toward it, feel more motivated to show beneficial organizational behaviors, and have the belief that their crafting efforts are valuable for the organization (Hur et al., 2017).

Recent studies have linked organizational identification and job crafting. Wang et al (2018) analyzed the moderating effect of employees' organizational identification on the relationship between transformational leadership and job crafting. They found that organizational identification reduces the effect of transformational leadership on adaptability and job crafting. The authors justify this result by pointing out that when employees are highly identified with their organizations, the influence of the leader on their interest in changing work conditions becomes weaker. Additionally, high organizational identification in employees may lead them to craft in favor of organizational goals (Brewer \& Chen, 2007), achieving higher levels of performance (Wang et al., 2016). In this line, Tuna et al. (2018), point out that several studies, such as those of Mauno et al. (2014), Muda et al., (2014), Neves (2012), Ziapour et al. (2014), reach the same conclusion. They state that.

those who identify with their organization and consider themselves a part of their organization make a greater effort for conducting their work, consider themselves as representatives of organization both inside and outside, and prioritize the benefits of organization in all their decisions (Tuna et al., 2018, p. 1708).

In this sense, Wang et al. (2017) pointed out that the effect of leadership on job crafting is buffered by organizational identification. In line with Tuna et al. (2018) and Wang et al. (2017), we consider that those employees highly identified with their organizations will also be more involved in job crafting activities intended to improve their results, and consequently, organizational identification interacts with job crafting when explaining perceived quality of care. In this sense, we propose the following hypotheses:
Hypothesis 2: Organizational identification (T1) moderates the relationship between job crafting (T1) and perceived quality of care (T2).

H2.a: Pride (T1) moderates the relationship between job crafting (task, relational and cognitive) (T1) and perceived quality of care (T2).

H2.b: Categorization (T1) moderates the relationship between job crafting (task, relational and cognitive) (T1) and perceived quality of care (T2).

H2.c: Cohesion (T1) moderates the relationship between job crafting (task, relational and cognitive) (T1) and perceived quality of care (T2).

The hypothesized model can be seen in Fig. 1.

\section{Method}

\section{Participants}

The participants were healthcare workers employed at 23 private and public nursing homes for the elderly in Spain and Sweden. The participating organizations from Sweden and Spain were selected by convenience. The participants were volunteers selected according to their accessibility and predisposition.

Out of the 928 employees contacted at T1, 628 returned completed questionnaires (68\% response rate). At time 2 , 890 employees were contacted and 501 answered (56\% response rate). A total of 226 employees answered at both $\mathrm{T} 1$ and $\mathrm{T} 2$. The $\mathrm{T} 1$ and $\mathrm{T} 2$ questionnaires were matched by means of anonymous codes, which the respondents created by using factual personal data.

We compared differences in sociodemographic variables among the participants only included in Wave 1 with those included in both Waves 1 and 2. The results indicate that there were no differences in age $(\mathrm{t}=-0.169, \mathrm{p}=0.866)$ and managerial position $(\chi 2=0.003, p=0.956)$. Differences were found in gender $(\chi 2=6.017, p=0.014)$ and contract $(\chi 2=8.589, p=0.003)$. Among participants in both waves, there was an increase in the percentage of women and permanent contracts in the second wave.

The sample consisted of 122 employees from four centers in Spain, and 82 employees from 19 centers in Sweden. It was a non-probabilistic accidental sample; participants were selected according to their accessibility or predisposition.

The description of sample characteristics is based on T1 data although a virtually identical description would have been obtained with $\mathrm{T} 2$ data. The participants were mostly female (91\% in Spain and $95.1 \%$ in Sweden) and the majority was between 43 and 63 years old $(56.3 \%$ in Spain and $72 \%$ in Sweden). The percentage of managers was $13.2 \%$ 
Fig. 1 Hypothesized model

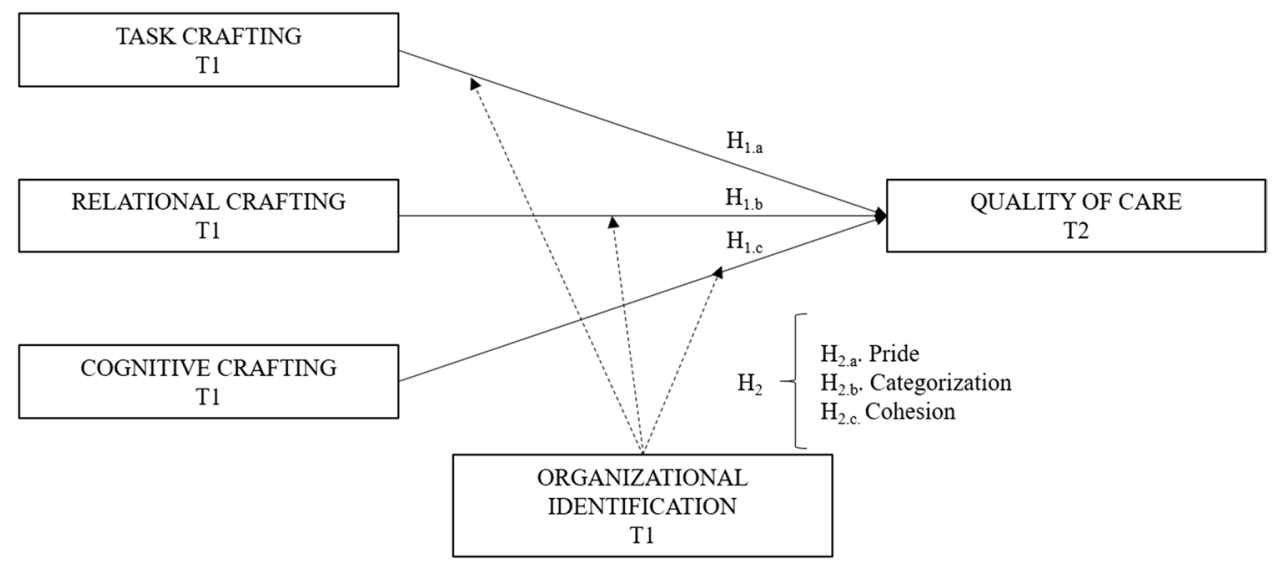

in Spain and $4.9 \%$ in Sweden. Finally, in most cases the employment contract was a permanent one $(92.4 \%$ in Spain and $92.7 \%$ in Sweden).

\section{Procedure}

The data in the study was collected in two waves (2015-2016) using an anonymous self-reporting questionnaire. We decided on an interval of 12 months (Cenciotti, et al., 2017) so as not to interfere with the everyday activities at the centers. At time 1, the Job Crafting Questionnaire (Slemp \& Vella-Brodrick, 2013) and the IdentificationCommitment Inventory (Quijano et al., 2000) were administered, while the Quality of Care Questionnaire (Westerberg \& Tafvelin, 2014) was administered at time 2. Sociodemographic data was collected in both waves.

All the participants received an informed consent form explaining the main research goals and procedure. All the questionnaires were completed using paper and pencil. In Sweden, the managers distributed the questionnaires to small groups of employees during working hours and participants were able to send their answers directly to the researchers by prepaid post. In Spain, the questionnaires were distributed and collected at the place of employment by the researchers.

Each participant created his/her own code following these instructions:

1. First initial of your mother's given name

2. Number of children (if you do not have children, write 0)

3. Last digit of your mobile phone number (if you do not have a mobile phone, write 0 )

4. First initial of your father's given name

The research project protocol was approved by the Regional Board of Ethics in Sweden (ref 2015-62-31Ö), and in Spain by the managers and research ethics committees of the participating centers (due to confidentiality agreements, the complete names of the participating centers cannot be disclosed). All participants gave informed consent for the research and their anonymity was preserved.

\section{Measures}

\section{Job crafting}

Job crafting was measured using the Job Crafting Questionnaire (JCQ) prepared by Slemp and Vella-Brodrick (2013), originally developed in English and based on Wrzesniewski and Dutton's theoretical framework (2001) and adapted to Spanish and Swedish (Yepes-Baldó et al., 2018). The Spanish and Swedish versions internal consistency was measured by Cronbach's alpha, with a result of 0.85 in Spain and 0.83 in Sweden (Yepes-Baldó et al., 2018).

The JCQ scale is a 15-item instrument that includes three subscales: Cognitive Crafting (JCQ Cognitive; five items; for example, "How often do you remind yourself of the importance of your work for the broader community?" $[\alpha=0.79$, Romeo et al., 2019]); Task Crafting (JCQ Task; five items; for example, "How often do you change the scope or types of tasks that you complete at work?" [ $\alpha=0.79$, Romeo et al., 2019]); and Relational Crafting (JCQ Relational; five items, such as "How often do you make friends with people at work who have similar skills or interests?" $[\alpha=0.71$, Romeo et al., 2019]). Participants responded to each item on a five-point Likert-type scale that ranged from 1 (hardly ever) to 5 (very often).

\section{Perceived quality of care}

Perceived quality of care was measured using the Quality of Care Questionnaire (QoC) prepared by Westerberg and Tafvelin (2014), developed originally in Swedish by 
Westerberg and Tafvelin (2014), and validated in Spanish by Yepes-Baldó et al. (2018). The internal consistency of the scale was $\alpha=0.86$ and $\alpha=0.81$ for the Swedish and Spanish versions, respectively. The $\mathrm{QoC}$ scale is a five-item instrument that features a unidimensional scale measuring the quality of care delivered according to the perception of the employees. The items are related to a) how often the respondent feels satisfied with the way in which the clients are treated, b) how well the clients are kept informed, c) how well their wishes are respected, d) how well help and support provided meet the clients' needs, and d) overall satisfaction with care work. For example: "At my workplace I feel that enough consideration is given to the users'/clients' opinions and wishes".

\section{Organizational identification}

Organizational identification was measured by the Identification-Commitment Inventory (Quijano et al., 2000). This is a six-item instrument with three subscales: Pride (two items; e.g. "I feel proud to work for this organization"), Categorization (two items; e.g. "I feel part of this Organization"), and Cohesion (two items; e.g. "I wish to continue to be a member of this company"). The original questionnaire was prepared in Spanish by Romeo et al. (2011) and following the guidelines provided by the World Health Organization (WHO, 2019). Its internal consistency was $\alpha=0.93$ (Romeo et al., 2011). The questionnaire was forward-translated, back-translated and pre-tested in Swedish. Participants responded to each item on a five-point Likert-type scale that ranges from 1 (totally disagree) to 5 (totally agree).

\section{Control variables}

In addition and based on previous job crafting and organizational identification research results, the questionnaire included sociodemographic data that were used as control variables. As regards country, Yepes-Baldó et al. (2018) found differences between Spain and Sweden when explaining organizational results. In relation to age, it has been demonstrated that older employees craft their jobs to adjust them to their personal preferences, motives, and abilities (Kooij et al., 2017). In the case of gender, there is evidence that relational crafting is higher among women than men (Slemp \& VellaBrodick, 2014). Finally, job characteristics have also been shown to have an effect on job crafting, including position - operative or manager (Berg et al., 2010; Tims et al., 2013), and type of contract - permanent or temporary (Piccoli et al., 2017).

\section{Data analysis}

The study consisted of a two-wave non-experimental survey design (with an interval of 12 months). Firstly, a confirmatory factor analysis (CFA) was carried out on the five perceived quality of care items, the fifteen job crafting items, and the six organizational identification items respectively, to check their fit with the theoretical structures. The analysis was carried out with AMOS 25 software. The maximum likelihood (ML) method was used for estimation. Additionally, we ran an invariance test to analyze measurement invariance for all constructs. Multi-group confirmatory factor analysis was used to test measurement invariance across countries for all constructs. Following Cheung and Rensvold (2002) we compared CFI for the unconstrained model and the measurement weights model. The reason is that even though measurement invariance was usually evaluated using the single criterion of significance of the change in $\chi^{2}$ for two nested models, "from a practical perspective, the $\chi 2$ difference test represents an excessively stringent test of invariance and particularly in light of the fact that SEM models at best are only approximations of reality" (Byrne, 2009, p. $221)$. A value of $\Delta$ CFI smaller or equal to 0.01 indicates that the measures are invariant across groups (Cheung \& Rensvold, 2002).

Secondly, descriptive statistics and correlations between study variables were calculated. To test the first hypothesis proposed, and after controlling for multicollinearity by mean-centering, we conducted hierarchical regression analysis. The dependent variable was perceived quality of care, measured at Time 2 (T2), and the independent variables were grouped into sets (Cohen et al., 2003). Set 1 included sociodemographic variables as control variables. Set 2 included the three job crafting variables (cognitive crafting, relational crafting, and task crafting) at Time 1 (T1).

Finally, PROCESS macro (model 1) for SPSS (Hayes, 2017) was used to analyze the moderation effect of organizational identification subdimensions (T1) on the direct relationship between job crafting subdimensions (T1) and perceived quality of care (T2). The pick-a-point approach and the Johnson-Neyman technique were used to graphically comprehend all hypothesized relationships (Hayes, 2017).

\section{Results}

\section{Confirmatory factor analyses}

As explained in the Measures section, all variables were measured by means of validated scales. Nevertheless, we ran a confirmatory factor analysis to ensure their fit with the theoretical constructs in our sample. 
All fit indices supported the three-factor model for job crafting at $\mathrm{T} 1$ (incremented fit index $[\mathrm{IFI}]=0.91$; comparative fit index $[\mathrm{CFI}]=0.92$; root mean square error of approximation $[\mathrm{RMSEA}]=0.068,90 \% \mathrm{CI}=[0.38,0.81])$, the one-factor model for quality of care at $\mathrm{T} 2$ (incremented fit index $[\mathrm{IFI}]=0.99$; comparative fit index $[\mathrm{CFI}]=0.99$; root mean square error of approximation $[\mathrm{RMSEA}]=0.056,90 \%$ $\mathrm{CI}=[0.29,0.85])$, and the three-factor model for organizational identification at $\mathrm{T} 1$ (incremented fit index $[\mathrm{IFI}]=0.99$; comparative fit index $[\mathrm{CFI}]=0.99$; root mean square error of approximation $[\mathrm{RMSEA}]=0.04,90 \% \mathrm{CI}=[0.0,0.10])$. The internal consistency for the global scales was also adequate (job crafting $\alpha=0.86$; quality of care $\alpha=0.83$; identification $\alpha=0.91)$.

As regards invariance, the test results showed that changes in the values of CFI were within the range of the recommended cutoffs, except for quality of care. The results were as follows: job crafting $\Delta \mathrm{CFI}=0.008$, identification $\Delta \mathrm{CFI}=0.004$, quality of care $\Delta \mathrm{CFI}=0.03$. This result could be due to the small sample in Sweden and, considering that it is near to the recommended cutoff of 0.01 we decided to accept it as invariant.

\section{Descriptive statistics and correlations}

Descriptive statistics for the major study variables are presented in Table 1. The participants performed moderate job crafting activities (T1) and had medium-high levels of identification with their organizations (T1). They also reported high levels of perception of quality of care (T2). Table 1 reports significant bivariate correlations between job crafting subscales (T1), the majority of subdimensions of organizational identification (T1) and perception of quality of care (T2). Specifically, task job crafting had a significant and positive correlation with perception of quality of care (T2), categorization and cohesion (T1), while relational and cognitive job crafting had a significant and positive correlation with perception of quality of care (T2) and the organizational identification subdimensions of pride, categorization, and cohesion (T1). Cronbach's alphas for the variables ranged from 0.81 to 0.85 , indicating good reliability for each scale.

\section{Test of hypothesis 1: Job crafting (T1) is positively associated with perceived quality of care (T2).}

Multicollinearity results were not problematic as all tolerance scores were higher than 0.90 (Tabachnick \& Fidell, 2001). Nevertheless, we controlled them by mean-centering all variables and, consequently, hierarchical regression analyses were performed. Significant regression coefficients were found in the analysis of the direct effect of job crafting subdimensions (T1) on perceived quality of care (T2) in the case of task crafting $\left(\beta=0.15 ; \mathrm{R}^{2}=0.05\right)$ and relational crafting $\left(\beta=0.18 ; \mathrm{R}^{2}=0.03\right)$.

In general, higher levels of task and relational job crafting (T1) were associated with higher levels of perceived quality of care (T2). However, the values of $\mathrm{R}^{2}$ in both cases indicated a slight variation in the dependent variable. Contrariwise, neither cognitive job crafting (T1) nor any of the control variables had a significant effect on perceived quality of care (T2). Accordingly, H1 was partially confirmed because $\mathrm{H} 1 \mathrm{a}$ and $\mathrm{H} 1 \mathrm{~b}$ were confirmed while H1c was not (Table 2).

\section{Test of hypothesis 2: Organizational identification (T1) moderates the relationship between job crafting (T1) and perceived quality of care (T2)}

Secondly, to analyze the moderating effect of identification subdimensions (T1), different separate tests for each of the job crafting and identification subdimensions were performed. As the control variables had been shown to have no significant effect, they were excluded from the analyses.

In relation to task crafting, there was no significant interaction effect between this and the organizational identification subdimensions. Furthermore, the results indicate that all organizational identification subdimensions had a simple effect on perceived quality of care (T2) when task

Table 1 Means, standard deviations, and correlations of variables $(n=226)$

\begin{tabular}{|c|c|c|c|c|c|c|c|c|c|c|c|}
\hline Variable & Min & Max & M & SD & 1.1 & 1.2 & 1.3 & 2.1 & 3.1 & 3.2 & 3.3 \\
\hline 1.1 Task Crafting (T1) & 1 & 5 & 3.22 & .75 & .78 & $.386 * *$ & $.465 * *$ & $.174 * *$ & .130 & $.257 * *$ & $.175^{* *}$ \\
\hline 1.2 Relational Crafting (T1) & 1 & 5 & 3.36 & .80 & & .76 & $.438 * *$ & $.24 * *$ & $.311 * *$ & $.334 * *$ & $.318^{* *}$ \\
\hline 1.3 Cognitive Crafting (T1) & 1 & 5 & 3.19 & .82 & & & .84 & $.155^{*}$ & $.185^{* *}$ & $.255^{* *}$ & $.231 * *$ \\
\hline 2.1 Quality of care (T2) & 2 & 5 & 4.03 & .61 & & & & .83 & $.315^{* *}$ & $.355 * *$ & $.363 * *$ \\
\hline 3.1 Pride (T1) & 1 & 5 & 3.96 & .81 & & & & & .89 & $.714 * *$ & $.72 * *$ \\
\hline 3.2 Categorization (T1) & 2 & 5 & 4.00 & .77 & & & & & & .82 & $.711 * *$ \\
\hline 3.3 Cohesion (T1) & 1.5 & 5 & 3.96 & .89 & & & & & & & .75 \\
\hline
\end{tabular}

$* \mathrm{p}<0.05, * * \mathrm{p}<0.01$, Cronbach's alpha in diagonal. $\mathrm{T} 1=$ Time $1, \mathrm{~T} 2=$ Time 2 
Table 2 Hierarchical regression results for quality of care (Time 2)

\begin{tabular}{|c|c|c|c|c|c|c|}
\hline & Variables & B & SE B & $\beta$ & $\mathrm{R}^{2}$ & $\Delta \mathrm{R}^{2}$ \\
\hline \multirow[t]{15}{*}{ TJC (T1) } & \multicolumn{4}{|c|}{ Model 1 (control variables) } & .026 & .026 \\
\hline & Constant & -.411 & .730 & & & \\
\hline & Country & -.011 & .148 & -.005 & & \\
\hline & Gender & .140 & .264 & .038 & & \\
\hline & Age & .005 & .006 & .062 & & \\
\hline & Permanent position & .526 & .297 & .128 & & \\
\hline & Managerial position & -.303 & .227 & -.096 & & \\
\hline & \multicolumn{4}{|c|}{ Model 2 (control and TJC) } & .047 & $.021^{*}$ \\
\hline & Constant & -.512 & .726 & & & \\
\hline & Country & -.013 & .146 & -.006 & & \\
\hline & Gender & .178 & .263 & .048 & & \\
\hline & Age & .005 & .006 & .057 & & \\
\hline & Permanent position & .488 & .295 & .119 & & \\
\hline & Managerial position & -.240 & .227 & -.076 & & \\
\hline & Task job crafting & $.147 *$ & .070 & $.147 *$ & & \\
\hline \multirow[t]{15}{*}{ CJC (T1) } & \multicolumn{4}{|c|}{ Model 1 (control variables) } & .026 & .026 \\
\hline & Constant & -.437 & .730 & & & \\
\hline & Country & -.029 & .147 & -.014 & & \\
\hline & Gender & .130 & .264 & .035 & & \\
\hline & Age & .006 & .006 & .070 & & \\
\hline & Permanent position & .521 & .296 & .126 & & \\
\hline & Managerial position & -.290 & .227 & -.091 & & \\
\hline & \multicolumn{4}{|c|}{ Model 2 (control and CJC) } & .041 & .015 \\
\hline & Constant & -.421 & .726 & & & \\
\hline & Country & -.032 & .146 & -.016 & & \\
\hline & Gender & .181 & .264 & .048 & & \\
\hline & Age & .005 & .006 & .062 & & \\
\hline & Permanent position & .475 & .296 & .115 & & \\
\hline & Managerial position & -.283 & .226 & -.089 & & \\
\hline & Cognitive job crafting & .126 & .071 & .124 & & \\
\hline \multirow[t]{15}{*}{ RJC (T1) } & \multicolumn{4}{|c|}{ Model 1 (control variables) } & .026 & .026 \\
\hline & Constant & -.437 & .730 & & & \\
\hline & Country & -.029 & .147 & -.014 & & \\
\hline & Gender & .130 & .264 & .035 & & \\
\hline & Age & .006 & .006 & .070 & & \\
\hline & Permanent position & .521 & .296 & .126 & & \\
\hline & Managerial position & -.290 & .227 & -.091 & & \\
\hline & \multicolumn{4}{|c|}{ Model 2 (control and RJC) } & .056 & $.030^{*}$ \\
\hline & Constant & -.203 & .726 & & & \\
\hline & Country & .060 & .149 & .029 & & \\
\hline & Gender & .134 & .261 & .036 & & \\
\hline & Age & .004 & .006 & .044 & & \\
\hline & Permanent position & .380 & .298 & .092 & & \\
\hline & Managerial position & -.298 & .224 & -.094 & & \\
\hline & Relational job crafting & $.184^{*}$ & .072 & $.182 *$ & & \\
\hline
\end{tabular}

Note: TJC, task job crafting; CJC, cognitive job crafting; RJC, relational job crafting; $* \mathrm{p}<.05 . * * \mathrm{p}<.01$ 
job crafting was average $(\mathrm{TJC}=0)$. In this case, as the variables had been mean-centered previously, the higher the levels of identification with the organization at Time 1 , the higher the perception of perceived quality of care at Time 2 among employees who did an average amount of task crafting. There was no significant effect of task crafting at Time 1 on perceived quality of care at Time 2 when organizational identification subdimensions were average (Table 3).

Results related to relational crafting indicate that all the organizational identification subdimensions had an effect on perceived quality of care (T2) when relational job crafting was average ( $\mathrm{RJC}=0)$, and, additionally, relational job crafting (T1) had an effect on perceived quality of care (T2) when the organizational identification subdimensions were average. In other words, higher levels of organizational identification at Time 1 were associated with higher levels of perceived quality of care at Time 2 among employees who did an average amount of relational crafting. Similarly, among employees at an average level in the organizational identification subdimensions, the higher the relational crafting score at Time 1, the higher the perceived quality of care at Time 2. Again, there was no interaction effect between relational job crafting and any of the organizational identification subdimensions (Table 4).

Finally, the interaction effects of pride, categorization, and cohesion on the relations between cognitive crafting (Time 1) and perceived quality of care (Time 2) were identified. In all cases, the interaction effect was only significant and positive in the case of high levels of organizational identification, with at least one standard deviation over the mean (Figs. 2, 3, and 4). That denotes that there only existed a significant positive relationship between cognitive job crafting at Time 1 and perceived quality of care at Time 2 among people with high levels (at least, one standard deviation over the mean) of pride, sense of belonging (categorization) and desire for continuity in the organization (cohesion). To obtain a more accurate description of the significance region, the Johnson-Neyman technique was used. The results indicate that the moderating effect was significant for Z-scores above 0.15 (for pride), 0.53 (for categorization), and 0.41 (for cohesion). These significance regions make up
Table 3 Analyses of the moderating effect of organizational identification on the relationship between task job crafting (TJC) (T1) and quality of care (T2)
Table 4 Analyses of the moderating effect of organizational identification on the relationship between relational job crafting (RJC) (T1) and quality of care (T2)

\begin{tabular}{llllllllll}
\hline Variables & Coefficient & $\mathrm{SE}$ & $\mathrm{t}$ & $\mathrm{LLCI}$ & $\mathrm{ULCI}$ & $\mathrm{R}^{2}$ & $\mathrm{R}^{2}$ change & MSE & $F$ \\
\hline Constant & -.007 & .064 & -.115 & -.133 & .118 & .123 & $<.001$ & .890 & $10.236^{* *}$ \\
TJC & .137 & .065 & $2.115^{*}$ & .009 & .264 & & & & \\
Pride & .307 & .064 & $4.790^{* *}$ & .181 & .433 & & & & \\
Interaction & .003 & .064 & .0480 & -.122 & .128 & & & & \\
Constant & -.026 & .065 & -.398 & -.153 & .102 & .145 & .005 & .868 & $12.398^{* *}$ \\
TJC & .094 & .065 & 1.437 & -.035 & .222 & & & & \\
Categorization & .353 & .065 & $5.407^{* *}$ & .224 & .482 & & & & \\
Interaction & .075 & .066 & 1.134 & -.055 & .204 & & & & \\
Constant & -.012 & .063 & -.185 & -.136 & .113 & .151 & $<.001$ & .862 & $12.967^{* *}$ \\
TJC & .118 & .064 & 1.845 & -.008 & .245 & & & & \\
Cohesion & .354 & .063 & $5.575^{* *}$ & .229 & .479 & & & & \\
Interaction & .028 & .061 & .460 & -.092 & .147 & & & & \\
\hline
\end{tabular}

Note: No standardized coefficient; TJC, task job crafting; SE, standard errors; LLCI, Lower-limit confidence interval; ULCI, Upper-limit confidence interval; MSE, mean-squared error; ${ }^{*} \mathrm{p}<.05 ;{ }^{* *} \mathrm{p}<.01$

\begin{tabular}{llllllll}
\hline Variables & Coefficient & $\mathrm{SE}$ & $\mathrm{t}$ & $\mathrm{R}^{2}$ & $\mathrm{R}^{2}$ change & MSE & $F$ \\
\hline Constant & -.003 & .066 & -.050 & .122 & $<.001$ & .890 & $10.242^{* * *}$ \\
RJC & .157 & .066 & $2.359^{*}$ & & & & \\
Pride & .267 & .067 & $4.009^{* *}$ & & & & \\
Interaction & .011 & .064 & .168 & & & & \\
Constant & -.005 & .065 & -.082 & .143 & $<.001$ & .869 & $12.282^{* *}$ \\
RJC & .136 & .066 & $2.055^{*}$ & & & & \\
Categorization & .311 & .066 & $4.676^{* *}$ & & & & \\
Interaction & .016 & .060 & .266 & & & .862 & $12.964^{* *}$ \\
Constant & -.009 & .065 & -.138 & .150 & $<.001$ & & \\
RJC & .139 & .065 & $2.121^{*}$ & & & & \\
Cohesion & .322 & .066 & $4.880^{* *}$ & & & & \\
Interaction & .028 & .061 & .462 & & & & \\
\hline
\end{tabular}

Note: No standardized coefficient; RJC, Relational job crafting; SE, standard errors; MSE, mean-squared error; $* \mathrm{p}<.05 ; * * \mathrm{p}<.01$ 
Fig. 2 Simple slopes of cognitive job crafting (T1) associated below, $1 \mathrm{SD}$ above, and exactly on the mean of pride to quality of care (T2) for $1 \mathrm{SD}$

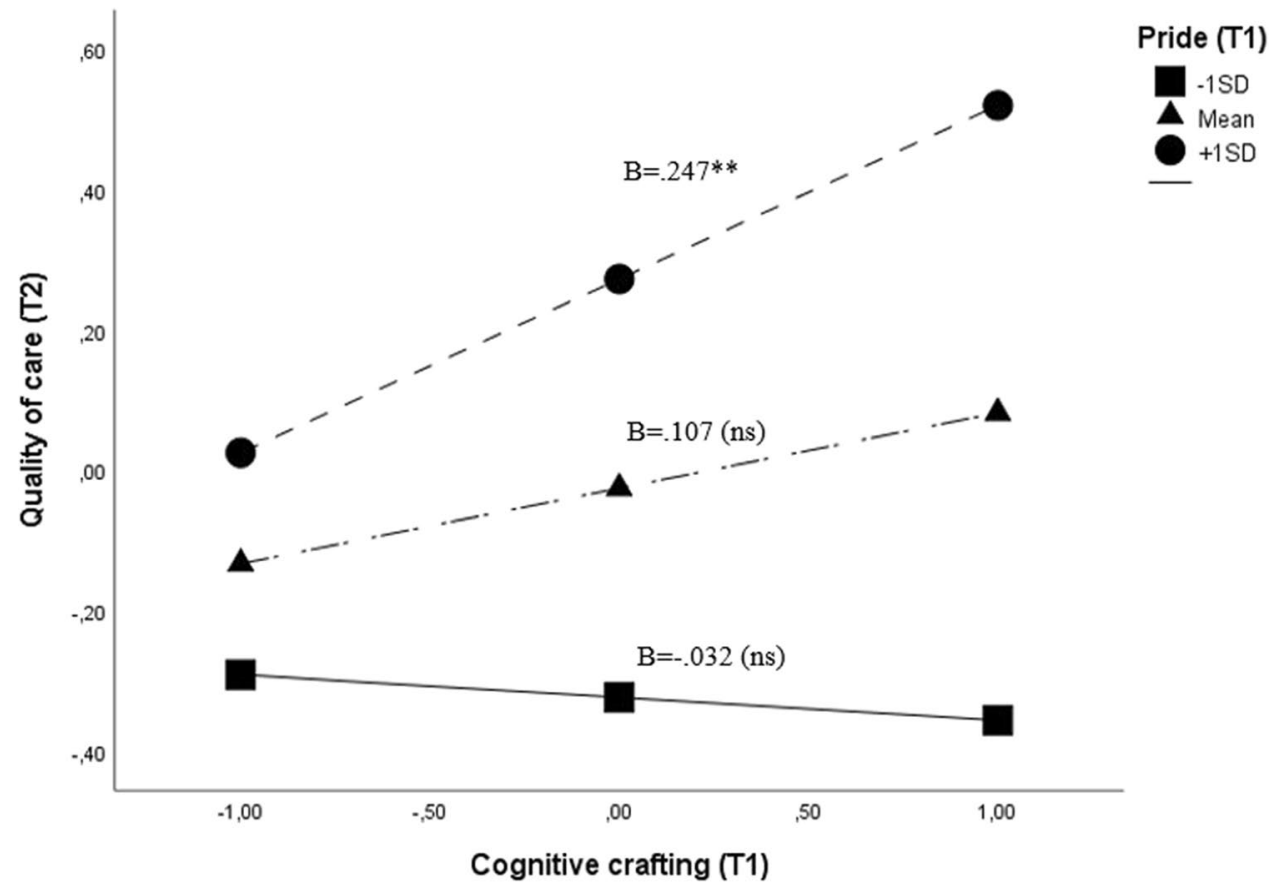

Fig. 3 Simple slopes of cognitive job crafting (T1) associated to quality of care (T2) for $1 \mathrm{SD}$ below, $1 \mathrm{SD}$ above, and exactly on the mean of categorization

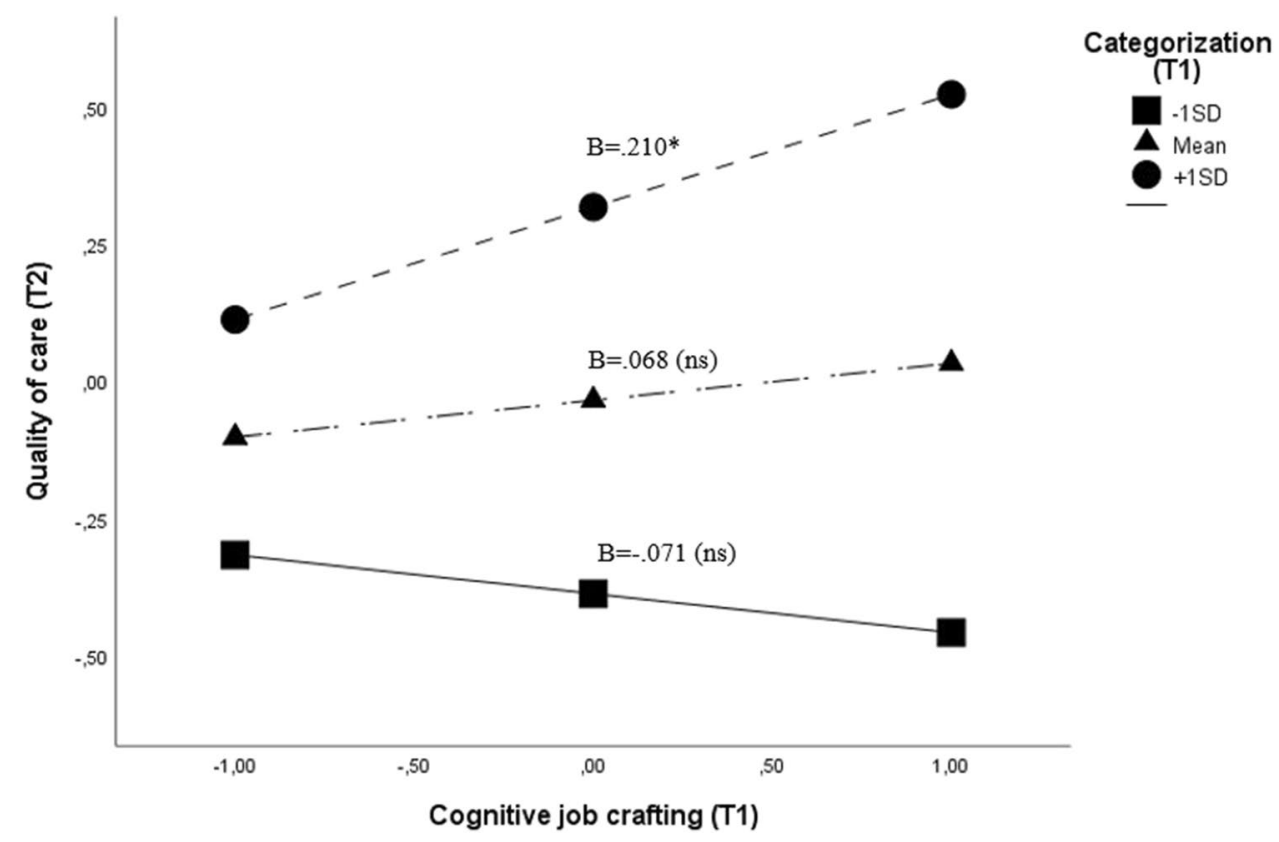

$34.67 \%$ of the sample for pride, $35.56 \%$ for categorization, and $39.11 \%$ for cohesion.

In addition to the moderating effect of organizational identification subdimensions on the relationship between cognitive crafting (T1) and perceived quality of care (T2), significant effects between all organizational identification subdimensions (T1) and perceived quality of care (T2) were identified. In this sense, the higher the organizational identification score at Time 1 , the higher the quality of care perception at Time 2 among employees with an average level of cognitive crafting (Table 5).

\section{Discussion}

The main goal of this research was to analyze the positive effect of job crafting activities carried out by nursing home employees on their perceived quality of care, 
Fig. 4 Simple slopes of cognitive job crafting (T1) associated to quality of care (T2) for $1 \mathrm{SD}$ below, $1 \mathrm{SD}$ above, and exactly on the mean of cohesion

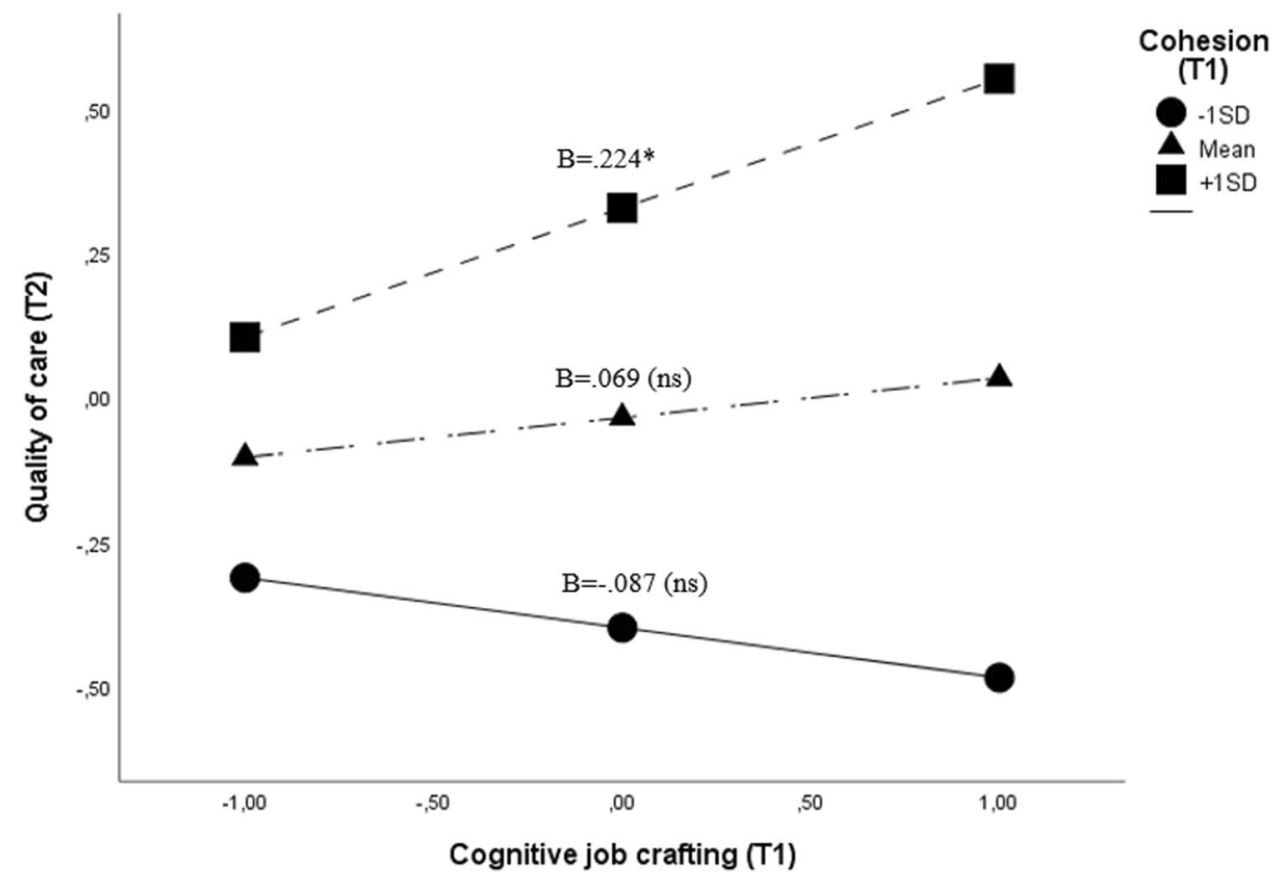

\begin{tabular}{llllllll}
\hline Variables & Coefficient & $\mathrm{SE}$ & $\mathrm{t}$ & $\mathrm{R}^{2}$ & $\mathrm{R}^{2}$ change & MSE & $F$ \\
\hline Constant & -.025 & .064 & -.399 & .128 & .019 & .883 & $10.854^{* *}$ \\
CJC & .107 & .064 & 1.680 & & & & \\
Pride & .297 & .064 & $4.663^{* *}$ & & & & \\
Interaction & .140 & .063 & $2.206^{*}$ & & & & \\
Constant & -.035 & .064 & -.548 & .151 & .020 & .861 & $13.057^{* *}$ \\
CJC & .068 & .064 & 1.053 & & & & \\
Categorization & .353 & .064 & $5.483^{* *}$ & & & & \\
Interaction & .138 & .060 & $2.288^{*}$ & & & .850 & $14.139^{* * *}$ \\
Constant & -.036 & .063 & -.562 & .161 & .024 & & \\
CJC & .069 & .063 & 1.086 & & & & \\
Cohesion & .364 & .063 & $5.716^{* *}$ & & & & \\
Interaction & .155 & .062 & $2.524^{*}$ & & & & \\
\hline
\end{tabular}

Note: No standardized coefficient; CJC, cognitive job crafting; SE, standard errors; MSE, mean-squared error; $* \mathrm{p}<.05 ; * * \mathrm{p}<.01$
Table 5 Analyses of the moderating effect of organizational identification on the relationship between cognitive job crafting (T1) and quality of care (T2) including organizational identification as a moderator of this relationship.

Our first hypothesis was that job crafting would have a direct effect on perceived quality of care in residential homes, as perceived by the employees. The results partially confirmed our hypothesis, given that a direct effect of task and relational crafting (T1) on perceived quality of care (T2) was identified. In this sense, the way employees did their jobs and the way they related to other co-workers had a direct effect on their perceptions of quality of care. However, no direct effect was found for cognitive crafting. These results are on some extent in the line of Leana et al. (2009), who found that job crafting activities that implies others to be done (collaborative job crafting) were strongly associated with quality of care in early education contexts. Contrarily, job crafting that individuals made on their own, more closed to cognitive crafting, were not relevant.

Traditionally, cognitive crafting has been considered a part of job crafting (Slemp \& Vella-Brodrick, 2013; Wrzeniewski \& Dutton, 2001; Wrzeniewski et al., 2003) that can affect performance, but other authors consider that cognitive, task and relational crafting should be regarded as aggregates but not indicators of the same construct (Romeo et al., 2020; Zhang \& Parker, 2019). Previous studies have pointed out that cognitive crafting may act as a mediator between task and relational crafting in the explanation of perceived quality of care (Romeo et al., 2020), showing the different relationship dynamics of task and relational job crafting, on the one hand, and of cognitive crafting, on the other. 
Our second set of hypotheses concerned the moderating role of the organizational identification subdimensions (T1) in the relationship between job crafting (T1) and perceived quality of care (T2). Again, our hypotheses were partially confirmed because the interaction effect was only found in the relationship between cognitive crafting (T1) and perceived quality of care (T2). Our results confirm the view of Slemp and Vella-Brodrick (2013), who consider that cognitive crafting is "the facet of job crafting that aligns most closely to "work identity", which is essentially how people define or perceive themselves at work (Slemp \& Vella-Brodrick, 2013, p. 138). This suggests that cognitive crafting has the capacity to help them "adopt a more positive and meaning view of their work, which may ultimately have corresponding influences on employee wellbeing, turnover, or engagement" (Slemp \& Vella-Brodrick, 2013, p. 140).

Our research extends the scarce knowledge of cognitive crafting, as pointed out by Hommelhoff et al. (2021). Cognitive crafting is an important way for employees to influence their work meaningfulness, work identity, and emotions (Berg et al., 2013; Lichtenthaler \& Fischbach, 2019 ; Wrzesniewski \& Dutton, 2001), and helps them to express what they value and what motivates them at work (Wrzesniewski et al., 2013). Our results suggest the need to rethink the job crafting construct, given that "not all jobs provide opportunities to change job content and therefore we need to encourage employees to create meaningful experiences by cognitively crafting their jobs" (Geldenhuys et al., 2021, p.92).

Recent studies (Zhang \& Parker, 2019) have indicated the existence of two opposed perspectives, approach job crafting and avoidance job crafting, based on Wrzesniewski et al., (2003, 2010, 2013) and Tims and Bakker (2010) respectively, and two types of crafting, behavioral and cognitive crafting. Behavioral crafting integrates task and relational crafting from a perspective of demands and resources. On the other hand, cognitive crafting includes also demands and resources (Zhang \& Parker, 2019 ). More recently, Melo et al. (2021) also advocated for the integration of both theoretical perspectives, specifying the role of behavior and cognition, and their relations. In this sense, our research adds more empirical evidence to the differential functioning of behavioral and cognitive crafting when explaining perceived quality of care.

\section{Limitations and future research}

Although this study makes an original contribution, there are some limitations that should be noted and addressed in future research. Firstly, the sample was not probabilistic, and our results cannot be generalized to all employees in nursing homes in Spain and Sweden or other countries. Additionally, some differences may be explained by the organizational culture of the nursing homes or other variables, as the profession or the level of education of the participants. Future research should include organizational variables as culture, organizational functioning, or level of aid assistance, and other individual variables as the level of education.

Secondly, even though our results did not report any effects specifically related to each country, the invariance test had shown that the instrument used to assess perception of quality of care was not equivalent among samples, although the result was near to the usual cutoff. The small sample size in Sweden and the fact that the instrument had been previously developed and created in Sweden, led us to go ahead with the analyzes globally. It should be noted that the perception of the quality of care may be affected by cultural factors. For example, in Sweden, quality is one of the principles of their working lives, while in Spain quality is a goal to be achieved (Hofstede, n.d). Therefore, the concept of perceived quality of care, being subjective at a qualitative level, can increase social desirability in staff responses. Studies that only compare two national cultures, such as in this research, are generally considered inadequate for proper cross-cultural comparisons (Zhang \& Parker, 2019). For this reason, we propose comparing samples obtained from more than two different cultural clusters in future research.

Thirdly, our research is based on the Wrzesniewski et al., (2003, 2010, 2013) approach, but when analyzing employees' identification with their organizations it could also be hypothesized that those who identify less might develop less desirable forms of crafting (e.g., reducing tasks and avoidance crafting). Future research should analyze both the approach and avoidance job crafting perspectives to gain further insight into this hypothesis. This could explain some of the inconsistent results we found in the present research.

Fourthly, the data was collected using self-report questionnaires (pencil and paper), and so the results may have been affected by subjective considerations, especially in the case of perceived quality of care. Therefore, future research should use self-report diaries and the evaluations provided by supervisors or co-workers, or objective indicators of performance, to overcome this limitation. Furthermore, with regard to the time interval between waves, it is important to consider the differences found in the drop-out analyses, which may be explained by the nature of the sector, with most employees being women with permanent contracts.

Additionally, the sample size should be increased, and other control variables, such as tenure, should be included, considering that several authors have confirmed the direct impact of length of tenure on organizational identification (Hall \& Schneider, 1972; Hall et al., 1970; Mael \& Ashforth, 1992). Increasing the sample size would allow to take into account the multilevel structure of the data collected, as employees are nested in work centers and countries, but unfortunately with the current data the analyzes could not be carried out. 


\section{Conclusion}

This research provides managers with guidance when allocating job crafting opportunities to achieve improvements in quality of care. It has been demonstrated that a demanding labor context in nursing homes encourages crafting behaviors (Berg et al., 2010), positively affecting work performance (Lichtenthaler \& Fischbach, 2019) in terms of longterm quality of care. Therefore, organizations should offer job crafting training to encourage and support their employees, thus helping to improve their quality of care (Gordon et al., 2018).

Job crafting intervention could offer a competitive advantage when coping with a high demands environment with poor working conditions and in organizational change contexts led by human resources, affecting quality of care (Lundmark et al., 2020; Westerberg et al., 2018). Managers can motivate employees to craft their jobs, gearing their needs, abilities, and goals to corporate values and competencies (Hulshof et al., 2020; Wang et al., 2016).

To sum up, cognitive crafting only had a positive effect on perceived quality of care among employees who were very proud of their organization, and among those who felt they were members of their organization and those who wanted to continue working there. In this sense, the implications of this research for the organizational context could be valuable for managers, human resources, and change agents. On the one hand, it is important to promote employees' autonomy, thereby helping them to carry out their tasks in a way suited to their interests and competences, and with organizational culture significantly contributing to the promotion of this autonomy and becoming a fundamental basis for job crafting (de Broek, 2019). And on the other hand, identification with the organization must be encouraged while giving meaning and significance to a type of employment that has sometimes been underestimated.

\section{Authors' contributions CriteriaAuthor Initials}

Made substantial contributions to conception and design, or acquisition of data, or analysis and interpretation of data;MR, MY-B, KW

Involved in drafting the manuscript or revising it critically for important intellectual content;MR, MY-B, PM

Given final approval of the version to be published. Each author should have participated sufficiently in the work to take public responsibility for appropriate portions of the content;MR, MY-B, MN, KW, RL, PM

Agreed to be accountable for all aspects of the work in ensuring that questions related to the accuracy or integrity of any part of the work are appropriately investigated and resolvedMR, MY-B, KW

Funding Open Access funding provided thanks to the CRUE-CSIC agreement with Springer Nature. The study was partial financial supported by the Swedish Research Council (FORTE) (Dnr 2015-00708).

Availability of data and material The datasets generated during and/or analyzed during the current study are available from the corresponding author on reasonable request.
Code availability (software application or custom code) Not applicable.

\section{Declarations}

Conflicts of interest/Competing interests The authors have no relevant financial or non-financial interests to disclose.

Ethics approval (include appropriate approvals or waivers) This study was performed in line with the principles of the Declaration of Helsinki. The protocol for the research project was approved by the Regional Board of Ethics in Sweden (ref 2015-62-31Ö), and by the managers and research ethics committees of the participating centers, in Spain (due to confidentiality agreements, the complete names of the participating centers cannot be disclosed).

Consent to participate (include appropriate statements) All participants gave informed consent for the research, and that their anonymity was preserved.

Consent for publication (include appropriate statements) Not applicable. Identifying information is not included in this article.

Conflict of interest On behalf of all authors, the corresponding author states that there is no conflict of interest.

Open Access This article is licensed under a Creative Commons Attribution 4.0 International License, which permits use, sharing, adaptation, distribution and reprofduction in any medium or format, as long as you give appropriate credit to the original author(s) and the source, provide a link to the Creative Commons licence, and indicate if changes were made. The images or other third party material in this article are included in the article's Creative Commons licence, unless indicated otherwise in a credit line to the material. If material is not included in the article's Creative Commons licence and your intended use is not permitted by statutory regulation or exceeds the permitted use, you will need to obtain permission directly from the copyright holder. To view a copy of this licence, visit http://creativecommons.org/licenses/by/4.0/.

\section{References}

Aiken, L., Clarke, S., \& Sloane, D. (2002). Hospital staffing, organization, and quality of care: Cross-national findings. Nursing Outlook, 50, 187-194. https://doi.org/10.1067/mno.2002.126696

Ang, H. S., Bartram, T., McNeil, N., Leggat, G. S., \& Stanton, P. (2013). The effects of high performance work systems on hospital employees' work attitudes and intention to leave: A multi-level and occupational group analysis. The International Journal of Human Resource Management, 24(16), 3086-3114. https://doi. org/10.1080/09585192.2013.775029

Bakker, A. B., Le Blanc, P., \& Schaufeli, W. (2005). Burnout contagion among intensive care nurses. Journal of Advanced Nursing, 51, 276-287. https://doi.org/10.1111/j.1365-2648.2005.03494.x

Berg, J., Dutton, J., \& Wrzesniewski, A. (2013). Job crafting and meaningful work. In B. Dik, Z. Byrne, \& M. Steger (Eds.), Purpose and meaning in the workplace (pp. 81-104). American Psychological Association.

Berg, J. M., Wrzesniewski, A., \& Dutton, J. E. (2010). Perceiving and responding to challenges in job crafting at different ranks: When proactivity requires adaptivity. Journal of Organizational Behavior, 31, 158-186. https://doi.org/10.1002/job.645 
Bobbio, A., \& Manganelli, A. M. (2015). Antecedents of hospital nurses' intention to leave the organization: A cross sectional survey. International Journal of Nursing Studies, 52(7), 1180-1192. https://doi.org/10.1016/j.ijnurstu.2015.03.009

Boumans, N., Berkhout, A., \& Landeweerd, A. (2005). Effects of resident oriented care on quality of care, wellbeing and satisfaction with care. Scandinavian Journal of Caring Science, 19, 240-250. https://doi.org/10.1111/j.1471-6712.2005.00351.x

Brewer, M. B., \& Chen, Y. R. (2007). Where (who) are collectives in collectivism? Toward conceptual clarification of individualism and collectivism. Psychological Review, 114, 133-151. https:// doi.org/10.1037/0033-295X.114.1.133

Brulin, C., Winkvist, A., \& Langendoen, S. (2000). Stress from working conditions among home care personnel with musculoskeletal symptoms. Journal of Advanced Nursing, 31, 181-189. https:// doi.org/10.1046/j.1365-2648.2000.01209.x

Cenciotti, R., Alessandri, G., \& Borgogni, L. (2017). Psychological capital and career success over time: The mediating role of job crafting. Journal of Leadership \& Organizational Studies, 24(3), 372-384. https://doi.org/10.1177/1548051816680558

Cheung, G. W., \& Rensvold, R. B. (2002). Evaluating goodness-of-fit indexes for testing measurement invariance. Structural Equation Modeling, 9(2), 233-255.

Cohen, J., Cohen, P., West, S., \& Aiken, L. (2003). Applied multiple regression/correlation analysis for the behavioral sciences. Routledge/taylor \& Francis Group. https://doi.org/10.4324/97802 03774441

Dennerstein, M., Bhar, S. S., \& Castles, J. J. (2018). A randomized controlled trial examining the impact of aged care residents' written life-stories on aged care staff knowledge and attitudes. International Psychogeriatrics, 30(9), 1291-1299. https://doi.org/10. 1017/S1041610217002800

Gordon, H. J., Demerouti, E., Le Blanc, P. M., Bakker, A. B., Bipp, T., \& Verhagen, M. A. (2018). Individual job redesign: Job crafting interventions in healthcare. Journal of Vocational Behavior, 104, 98-114. https://doi.org/10.1016/j.jvb.2017.07.002

Hall, D. T., \& Schneider, B. (1972). Correlates of organizational identification as a function of career pattern and organizational type. Administrative Science Quarterly, 17(3), 340-350.

Hall, D. T., Schneider, B., \& Nygren, H. T. (1970). Personal factors in organizational identification. Administrative Science Quarterly, $15,176-190$.

Hamzagić, E. (2018). The importance of the organizational identification in forming organizational perception. Faculty of Business Economics and Entrepreneurship International Review, 1-2, 31-38.

Hasson, H., \& Arnetz, J. (2009). The impact of an educational intervention on nursing staff ratings of quality of older people care: A prospective, controlled intervention study. International Journal of Nursing Studies, 46, 470-478. https://doi.org/10.1016/j.ijnur stu.2008.04.007

Hayes, A. F. (2017). Introduction to mediation, moderation, and conditional process analysis: A regression-based approach (2nd ed.). The Guilford Press.

Hulshof, I. L., Demerouti, E., \& Le Blanc, P. M. (2020). Providing services during times of change: Can employees maintain their levels of empowerment, work engagement and service quality through a job crafting intervention? Frontiers in Psychology, 11, a87. https://doi.org/10.3389/fpsyg.2020.00087

Hur, W. M., Shin, Y., Rhee, S. Y., \& Kim, H. (2017). Organizational virtuousness perceptions and task crafting: The mediating roles of organizational identification and work engagement. Career Development International, 22(4), 436-459. https://doi.org/10. 1108/CDI-11-2016-0192
Leana, C., Appelbaum, E., \& Shevchuk, I. (2009). Work process and quality of care in early childhood education: The role of job crafting. Academy of Management Journal, 52(6), 1169-1192.

Lee, J. Y., \& Lee, Y. (2018). Job crafting and performance: Literature review and implications for human resource development. Human Resource Development Review, 17(3), 277-313. https://doi.org/10. $1177 / 1534484318788269$

Lichtenthaler, P. W., \& Fischbach, A. (2019). A meta-analysis on promotion- and prevention- focused job crafting. European Journal of Work and Organizational Psychology, 28, 30-50. https://doi. org/10.1080/1359432X.2018.1527767

Lood, Q., Kirkevold, M., Sjögren, K., Bergland, Å., Sandman, P. O., \& Edvardsson, D. (2019). Associations between person-centred climate and perceived quality of care in nursing homes: A crosssectional study of relatives' experiences. Journal of Advanced Nursing, 75, 2526-2534. https://doi.org/10.1111/jan.14011

Lundgren, D., Ernsth Bravell, M., Börjesson, U., \& Kåreholt, I. (2020). The association between psychosocial work environment and satisfaction with old age care among care recipients. Journal of Applied Gerontology, 39(7), 785-794. https://doi.org/10.1177/ 0733464818782153

Lundmark, R., Nordin, M., Yepes-Baldó, M., Romeo, M., \& Westerberg, K. (2020). Cold wind of change: Associations between organizational change, turnover intention, overcommitment and quality of care in Spanish and Swedish eldercare organizations. Advance online publication. https://doi.org/10.1002/nop2.615

Mael, F. A., \& Ashforth, B. E. (1992). Alumni and their alma mater: A partial test of the reformulated model. Journal of Organizational Behavior, 13(2), 103-123.

Mauno, S., DeCuyper, N., Tolvanen, A., Kinnunen, U., \& Makikangas, A. (2014). Occupational well-being as a mediator between job insecurity and turnover intention: Findings at the individual and work department levels. European Journal of Work and Organizational Psychology, 23(3), 381-393. https://doi.org/10.1080/13594 32X.2012.752896

Mckenzie, J. A. L., Blandford, A. A., Menec, V. H., Boltz, M., \& Capezuti, E. (2011). Hospital nurses' perceptions of the geriatric care environment in one Canadian health care region. Journal of Nursing Scholarship, 43, 181-187. https://doi.org/10.1111/j. 1547-5069.2011.01387.x

Melo, N., Dourado, D., \& Andrade, J. (2021). Reclaiming cognitive crafitng: An integrative model of behavioral and cognitive practices in job crafting. International Journal of Organizational Analysis. https://doi.org/10.1108/IJOA-04-2020-2130

Moore, K. (2018). Quality of care for frail older adults. International Psychogeriatrics, 30, 1255-1257. https://doi.org/10.1017/S1041 610218001321

Neves, P. (2012). Organizational cynicism: Spillover effects on supervisor-subordinate relationship and performance. The Leadership Quarterly, 23(5), 965-976. https://doi.org/10.1016/j.leaqua.2012. 06.006

Niessen, C., Weseler, D., \& Kostova, P. (2016). When and why do individuals craft their jobs? The role of individual motivation and work characteristics for job crafting. Human Relations, 69, 1287-1313.

Petrou, P., Demeuroti, E., Peeters, M., Schaufeli, W., \& Hetland, J. (2012). Crafting a job on daily basis: Contextual correlates and the link to work engagement. Journal of Organizational Behavior, 33, 1120-1141. https://doi.org/10.1002/job.17837

Piccoli, B., Callea, A., Urbini, F., Chirumbolo, A., Ingusci, E., \& De Witte, H. (2017). Job insecurity and performance: The mediating role of organizational identification. Personnel Review, 46(8), 1508-1522. https://doi.org/10.1108/PR-05-2016-0120

Purdy, N., Spence Laschinger, H., Finegan, J., Kerr, M., \& Olivera, F. (2010). Effects of work environments on nurse and patient 
outcomes. Journal of Nursing Management, 18, 901-913. https:// doi.org/10.1111/j.1365-2834.2010.01172.x

Quijano, S., Navarro, J., \& Cornejo, J. M. (2000). Un modelo integrado de compromiso e identificación con la organización: Análisis del cuestionario ASH-ICI. Revista De Psicología Social Aplicada, $10,27-61$.

Røen, I., Kirkevold, Ø., Testad, I., Selbæk, G., Engedal, K., \& Bergh, S. (2017). Person-centered care in Norwegian nursing homes and its relation to organizational factors and staff characteristics: A crosssectional survey. International Psychogeriatrics, 30, 1279-1290. https://doi.org/10.1017/S1041610217002708

Romeo, M., Yepes, M., Berger, R., Guàrdia, J., \& Castro, C. (2011). Identification-Commitment Inventory (ICI Model): Confirmatory factor analysis and construct validity. Quality and Quantity, 45, 901-909. https://doi.org/10.1007/s11135-010-9402-0

Romeo, M., Yepes-Baldó, M., Piñeiro, M. Á., Westerberg, K., \& Nordin, M. (2019). Job crafting and well-being in the elderly care sector: The effect of over-commitment. Employee Relations, 41(3), 405-419. https://doi.org/10.1108/ER-04-2018-0117

Romeo, M., Yepes-Baldó, M., Westerberg, K., \& Nordin, M. (2018). Impact of job crafting on quality of care: The moderating effect of commitment. Psychology, 9, 2649-2661. https://doi.org/10.4236/ psych.2018.912151

Scheepers, R., Arah, O., \& Heineman, M. (2014). In the eyes of resident's good supervisors need to be more than engaged physicians: The relevance of teacher work engagement in residency training. Advance Health Science Education, 20, 441-455. https://doi.org/ 10.1007/s10459-014-9538-0

Stimpfel, A. W., Djukic, M., Brewer, C. S., \& Kovner, C. T. (2019). Common predictors of nurse-reported quality of care and patient safety. Health Care Management Review, 44, 57-66. https://doi. org/10.1097/HMR.0000000000000155

Tadić, M. (2019). Personal resources and work engagement: A twowave study on the role of job resources crafting among nurses. Društvena Istraživanja: Časopis Za Opća Društvena Pitanja, 28, 5-24. https://doi.org/10.5559/di.28.1.01

Tims, M., \& Bakker, A. B. (2010). Job crafting: Towards a new model of individual job redesign. SA Journal of Industrial Psychology, 36, 1-9. https://doi.org/10.4102/sajip.v36i2.841

Tims, M., Bakker, A. B., \& Derks, D. (2013). The impact of job crafting on job demands, job resources, and well-being. Journal of Occupational Health Psychology, 18, 230-240. https://doi.org/ 10.1037/a0032141

Tummers, L. G., Groeneveld, S. M., \& Lankhaar, M. (2013). Why do nurses intend to leave their organization? A large-scale analysis in long-term care. Journal of Advanced Nursing, 69(12), 2826-2838. https://doi.org/10.1111/jan.12249

Tyler, T. R., \& Blader, S. L. (2003). The group engagement model: Procedural justice, social identity, and cooperative behavior. Personality and Social Psychology Review, 7(4), 349-361. https:// doi.org/10.1207/S15327957PSPR0704_07

van Knippenberg, D., \& Schie, E. C. M. (2000). Foci and correlates of organizational identification. Journal of Occupational and Organizational Psychology, 73, 137-147. https://doi.org/10.1348/ 096317900166949

Van Knippenberg, D., \& Sleebos, E. (2006). Organizational identification versus organizational commitment: Self-definition, social exchange, and job attitudes. Journal of Organizational Behavior: The International Journal of Industrial, Occupational and Organizational Psychology and Behavior, 27(5), 571-584.

Verho, H., \& Arnetz, J. (2003). Validation and application of an instrument for measuring patient relatives' perception of quality of geriatric care. International Journal for Quality in Health Care, 15, 197-206. https://doi.org/10.1093/intqhe/mzg030

Vernooij-Dassen, M., \& Moniz-Cook, E. (2016). Person-centered dementia care: Moving beyond caregiving. Aging and Mental
Health, 20, 667-668. https://doi.org/10.1080/13607863.2016. 1154017

Wagner, C., Van der Wal, P., Groenewegen, P., \& Bakker, D. (2001). The effectiveness of quality systems in nursing homes: A review. Quality in Health Care, 10, 211-217. https://doi.org/ 10.1136/qhc.0100211

Wang, H. J., Demerouti, E., \& Bakker, A. B. (2016). A review of job crafting research. In S. K. Parker \& U. K. Bindl (Eds.), Proactivity at work: Making Things Happen in Organizations (pp. 77-104). Routledge.

Wang, H. J., Demerouti, E., \& Le Blanc, P. (2017). Transformational leadership, adaptability, and job crafting: The moderating role of organizational identification. Journal of Vocational Behavior, $100,185-195$.

Westerberg, K., \& Tafvelin, S. (2014). The importance of leadership style and psychosocial work environment to staff-assessed quality of care: Implications for home help services. Health and Social Care in the Community, 22, 461-468. https://doi.org/10. 1111/hsc. 12084

Wrzeniewski, A., \& Dutton, J. E. (2001). Crafting a job: Revisioning employees as active crafters of their work. Academy of Management Review, 26, 179-201. https://doi.org/10.2307/259118

Wrzesniewski, A., Dutton, J. E., \& Debebe, G. (2003). Interpersonal sensemaking and the meaning of work. Research in Organizational Behavior, 25, 93-135. https://doi.org/10.1016/S01913085(03)25003-6

Yepes-Baldó, M., Romeo, M., Westerberg, K., \& Nordin, M. (2018). Job crafting, employee well-being, and quality of care. Western Journal of Nursing Research, 40(1), 52-66. https://doi.org/10. 1177/0193945916680614

Zhang, F., \& Parker, S. (2019). Reorienting job crafting research: A hierarchical structure of job crafting concepts and integrative review. Journal of Organizational Behavior, 40, 126-146. https://doi.org/10.1002/job.2332

Ziapour, A., Khatony, A., Kianipour, N., \& Jafary, F. (2014). Identification and analysis of labor productivity components based on ACHIEVE model (case study: Staff of Kermanshah University of Medical Sciences). Global Journal of Health Science, 7(1), 315-321. https://doi.org/10.5539/gjhs.v7n1p315

Bacaksiz, F. E., Tuna, R., \& Seren, A. K. H. (2017). The relationships between organisational identification, job performance, and job crafting: A study among nurses. International Journal of Caring Sciences, 10(1), 251-259. http://www.internationaljo urnalofcaringsciences.org/docs/29_bacaksiz_original_10_1.pdf

Byrne, B. M. (2009). Structural equation modeling with AMOS: Basic concepts, programming, and applications. RoutledgeTaylor \& Francis Group

de Broek, L. V. D. (2019). The influence of organizational culture on job crafting. A qualitative study on how the organizational culture of Philips Design influences their employees' job crafting behaviour [Unpublished master thesis]. Radboud Universiteit. https://theses.ubn.ru.nl/handle/123456789/8891?locale-attri bute $=$ en

Geldenhuys, M., Bakker, A. B. \& Demerouti, E. (2021). How task, relational and cognitive crafting relate to job performance: a weekly diary study on the role of meaningfulness. European Journal of Work and Organizational Psychology, 30 (1), 83-94. https://doi.org/10.1080/1359432X.2020.1825378

Genet, N., Boerma, W., Kroneman, M., Hutchinson, A., \& Saltman, R. B. (Eds.). (2012). Home care across Europe: Current structure and future challenges. European Observatory on Health Systems and Policies. https://www.nivel.nl/sites/default/files/ bestanden/Home-care-across-Europe-case-studies.pdf

Hofstede, G. (n.d). Hofstede Insights. Country comparison. Retrieved October 16, 2020, from https://www.hofstede-insights.com/count ry 
Hommelhoff, S., Weseler, D., \& Niessen, C. (2021). The role of cognitive job crafting in the relationship between turnover intentions, negative affect, and task mastery. Anxiety, Stress, \& Coping. https://doi.org/10.1080/10615806.2021.1892653

Kilic, E., Tatar, B., \& Erdil, O. (2020). The relationship between job crafting and organizational identification: The mediating role of affective well-being. Business and Economics Research Journal, 11(1), 201-212. https://doi.org/10.20409/berj.2020.245

Kooij, D. T. A. M., van Woerkom, M., Wilkenloh, J., Dorenbosch, L., \& Denissen, J. J. A. (2017). Job crafting towards strengths and interests: The effects of a job crafting intervention on person-job fit and the role of age. Journal of Applied Psychology, 102(6), 971-981. https://doi-org.sire.ub.edu/10.1037/ap10000194

Muda, I., Rafiki, A., \& Harahap, M. R. (2014). Factors influencing employees' performance: a study on the Islamic Banks in Indonesia. International Journal of Business and Social Science, 5(2), 73-80. http://ijbssnet.com/journals/Vol_5_No_2_Febru ary_2014/9.pdf

Neves, T. M. A., Parreira, P. M. S. D., Graveto, J. M. G. N., dos Santos de Freitas, M. J. B., \& Rodrigues, V. J. L. (2020). Nurse managers' perceptions of nurse staffing and nursing care quality: a cross-sectional study. Journal of Nursing Management, 1-23.https://doi. org/10.1111/jonm.12966

Roberts, J. S. (1987). Reviewing the quality of care: priorities for improvement. Health Care Financing Review, Supplement., 69-74. https://www.ncbi.nlm.nih.gov/pmc/articles/PMC4195091/

Romeo, M., Yepes-Baldó, M., Westerberg, K., \& Nordin, M. (2020). Cognitive job crafting as mediator between behavioral job crafting and quality of care in residential homes for the elderly. Plos One, 15(12), e0243726.

Slemp, G. R., \& Vella-Brodrick, D. A. (2013). The job crafting questionnaire: A new scale to measure the extent to which employees engage in job crafting. International Journal of Wellbeing, 3(2), 126-146. https://www.internationaljournalofwellbeing.org/index. php/ijow/article/view/217

Slemp, G. R., \& Vella-Brodrick, D. A. (2014). Optimising employee mental health: The relationship between intrinsic need satisfaction, job crafting, and employee well-being. Journal of Happiness Studies, 15(4), 957-977. https://doi.org/10.1007/ s10902-013-9458-3
Tabachnick, B. G., \& Fidell, L. S. (2001). Using Multivariate Statistics (4th Ed). Allyn \& Bacon.

Tuna, R., Bacaksiz, F. E., \& Seren, A. K. H. (2018). The effects of organizational identification and organizational cynicism on employee performance among nurses. International Journal of Caring Sciences, 11, 1707-1714. http://www.internationaljournal ofcaringsciences.org/docs/42_bakaksiz_original_11_3.pdf

Wang, H., Wang, L., \& Liu, C. (2018). Employee competitive attitude and competitive behavior promote job-crafting and performance: A two-component dynamic model. Frontiers in Psychology, 9, Article e02223. https://doi.org/10.3389/fpsyg.2018.02223

Westerberg, K., Pienaar, J., Nordin, M., Romeo, M., \& Yepes-Baldó, M. (2018). Organizational change and commitment: Effects on well-being, turnover intent, and quality of care in Spanish and Swedish eldercare. Economic and Industrial Democracy. Advance online publication. https://doi.org/10.1177/0143831X18815970

World Health Organization (WHO) (2016). Standards for improving quality of maternal and newborn care in health facilities. https:// apps.who.int/iris/bitstream/handle/10665/249155/9789241511 216-eng.pdf?sequence $=1$

World Health Organization (WHO). (2019). Process of translation and adaptation of instruments. https://www.who.int/substance_abuse/ research_tools/translation/en/

Wrzesniewski, A., Berg, J., \& Dutton, J. E. (2010). Managing yourself: Turn the job you have into the job you want. Harvard Business Review, June. https://www.theplaygroundcpm.com/uploa ds/80239/files/WWCC_-_Working_with_children_background_ check_consent.pdf

Wrzesniewski, A., LoBuglio, N., Dutton, J. E., \& Berg, J. M. (2013). Job crafting and cultivating positive meaning and identity in work. In A. B. Bakker (Ed.), Advances in positive organizational psychology (Vol. 1.) (p. 281-302). Emerald Group Publishing. https:// doi.org/10.1108/S2046-410X(2013)0000001015

Yaghoubi, M., Javadi, M., Rakhsh, F., \& Bahadori, M. (2013). A study of determining factors affecting the performance of nurses based on the achieve model in selected hospital of Isfahan (Iran). Journal of Education and Health Promotion, 2(1), Article 49. https:// doi.org/10.4103/2277-9531.119033

Publisher's note Springer Nature remains neutral with regard to jurisdictional claims in published maps and institutional affiliations. 